\title{
JUAN ZORRILLA DE SAN MARTÍN Y GUSTAVO ADOLFO BÉCQUER
}

\section{Introducción}

No scria novedad señalar en Zorrilla San Martín un claro influjo becqueriano, si nos quedáramos en esa simple advertencia. El gran papel que el poeta sevillano juega, por muchos conceptos, en la poesía posterior, no se limitó a la I'enínsula, y los cjemplos pueden multiplicarse al otro laclo del $\Lambda$ tlántico. Zorrilla de San Martín ha sido uno de los que acusaron más hondamente su impacto. Lo acusó, además, con una prontitud, con una inmediatez, que dice mucho del eco potente y amplio que el poeta de las Rimas consiguió rápidamente.

Nacido el poeta uruguayo en $1855,{ }^{1}$ su primer libro poético, Notas de un himno, es de $\mathrm{I} 877^{2}$ y ya de él se ha dicho: "La presencia de Bécquer, tan acusada luego en Tabaré, se descubre desde el primer instante" ${ }^{3}$.

Pero el impacto profunclo del sevillano se observa en su mejor obra, algunos años más tarde: La leyenda patria (I879), y, sobre todo, en Taburé (1888) ${ }^{4}$.

A esas obras, y en especial a la última, vamos a dedicar este trabajo, en relaciớn con las Rimas de Bécquer, pasando de la indicación difusa del aire becqueriano a los puntos concretos en que dicho influjo se patentiza claramente.

\section{Notas de un himno}

Hace sólo siete años que Bécquer ha muerto, y menos aún que se han publicado sus obras, $y$, sin embargo, los primeros poemas de Zo-

1 Juan Zorritid in: San Martin, Obras Completas. Vol. I; Versos. Notas de un himno. Montevideo. Imprenta Nacional Colorada. 1930, p. 224.

2 Gustavo Anordio BÉCQUi:k, Obras Completas, Madricl. Aguilar, 1954, pp. $438-40$.

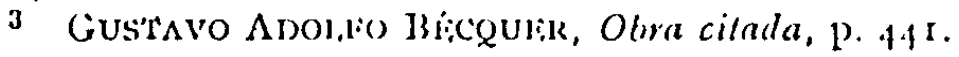

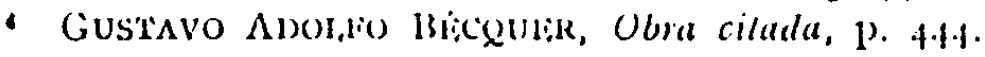


rrilla de San Martín, Notas de un hımno, de 1877 , según hemos indicado, demuestran ya una evidente influencia becqueriana.

Señalada repetidamente esa influencia, sólo queremos evidenciarla un tanto pormenorizadamente, para completarla más adelante con La lcycuda patria y Tabaré, de mucha más importancia (y calidad) eil lia obra del uruguayo.

Credo.-

Es el primero de los poemas del libro, y en él, la siguiente estrofa:

Las ideas, cual aitomos, circulan, $y$, cual vibrantes estrelladas olas, sucrgen del éter, palpitando ondulan, se pierden en confusas autreolas. y salpican mi frente las cascadas de luz inleligenle ${ }^{1}$.

nos hace recordar la rima flI de Bécquer:

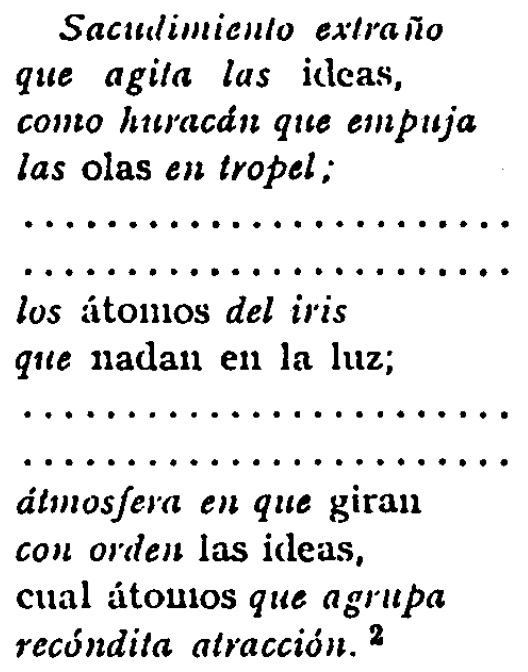

1 Gustayo Adolfo Béceuik, Obra cilada, p. 447. El poema Mirjer (Obra cilada de ZorriL,A SAN MLARTín, p. 247), tampoco es ajeno, en algunos pasajes a esta rima $\mathrm{X}$ :

\author{
Entre perdidos sones \\ de batir de alas, de vibrar suspiros, \\ que van y vienen en risueños giros.
}

2 Ilasta aquí comparando palabras del poeta americano (Obra cilada, pp. 23223.3), con las de Bćc(puer en la rima $\mathrm{XV}$. 
y alu la IV:

Mientras las ondas de la luz al beso palpiten encendidas... ${ }^{1}$.

la V:

Yo ondulo con los átomos ${ }^{2}$.

y la $\mathrm{x}$ :

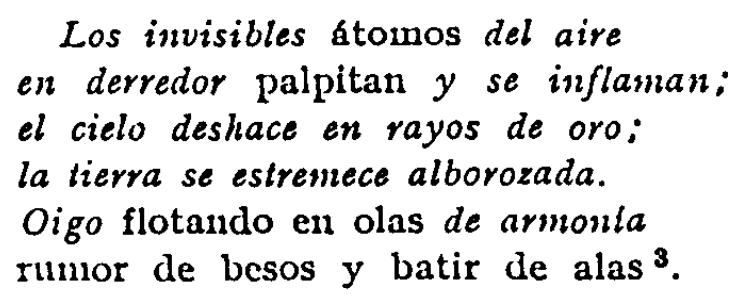

Tii $y$ yo:-

Isstructura típicamente becqueriana, como se ha señalado, en ese dualismo en contraste; con la exposición de cualidades, atributos de un sujeto que sólo al final poéticamente se expresa: "Eso es tu aliento", en pie quebrado de clara resonancia ("eso eres túu).

En la equivalencia de imágenes: "rumor de oleaje... en desierta orilla", frente a "en mar sin playas, onda sonante" 4 .

Fin esa poética transformación del becqueriano "en el laúd soy notan ${ }^{5}$, en aquellos dos bellísimos versos del poeta uruguayo:

Nota que, al desprenderse de una cuerda, deja al pobre laitd, temblando, herido.

1 Rima;V. Obra cilada, p. 443.

2 \%orril.ta SAN MLATtin, Obra cilada, p. 242.

3 Bíçule, Obra citada, p. 438. No olvidemos, por otra parte, respecto al verso "como arenal de fuego", aquel de la rima $V$ del sevillano: "soy fuego en las arenasn. Is asombroso el conjunto de resonancias que por todas partes aparecen. ¿Q.uién al leer ese "envuclta en su cendal de espumas", del poema Bellini de Zorrilla San Martin, no recuerda:

Cendal flolanle de leve bruma. rizada cinta de blanca espuma...

de la rima $\mathrm{XV}$, o el "olas gigantes... / .. / envuelto entre las sábanas de espuma...", de la rima I,II, ambas del poeta español?.

- \%orkibia San Mak'ín, Obra cilada, p. 245.

- ZukRir,i, SAN Martín, Obra cilada, p. 247. 
Véanse, finalınente, por no insistir demasiado en lo evidente, dos versos aún, de Zorrilla San Martín:

Roce de $u n$ alma que, buscando otra alina, en sl mismo sin ruido se desliza

frente a aquellos de la rima IX de Bécquer:

La llama cu derredor del tronco ardiente por besar a otra llama se desliza.

La inspiracion.-

La forma expositiva (semejante a la del poema anterior), el tema, el netro, ritmo y léxico, derivan abrumadoramente de las rimas III y $V$ de Bécquer. Citaremos tan sólo un fragmento (podría hacerse con todo el poema) del poeta amcricano:

\author{
licuolución de ideas \\ que nacen, chocan, muleren, \\ como arcual de fisego \\ 'en ciega agitación... '.
}

Compárese con la rima III:

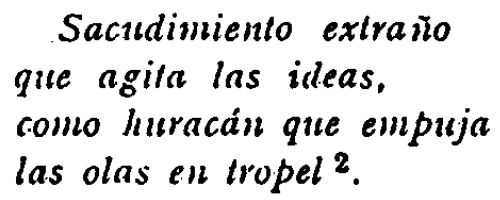

Siemprevivas.-

Creemos que su segunda estrofa:

Al no poder llorar, vien los hombres, y, al miralos pasar, causan envidia. iSiemprevivas! si el bien tiene su llanto, tiene el dolor también su amarga risa ${ }^{3}$.

es un recuerdo de la rima XLIX becqueriana: "Alguna vez la encuentro por el mundo...). Asunto, léxico (risa, pasar junto a, amarga risa, máscara del dolor...)..., todo se asemeja confirmadoramente.

1 BécQui:r, Obra ciladla, 1). 490. Rima LXXVI.

2 ZoRRILIA SAN MARTiN, Obra cilada, p. 254.

3 BịcQulik, Obra cilada, p. qsi. Rima J,XxI. 
Buscad al ángel.-

..... comio avaro sie tesoro,

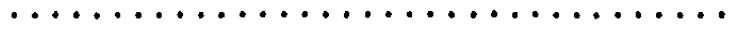

guardó su inspiración dentro del alma '.

Así dice, fragmentariamente, la tercera estrofa de este poema, y bastan esas palabras escogidas para recordar la conocida rima LXIV:

Como guarda el avaro su tesoro, guardaba mi dolor.

con idéntico ritmo (y no sólo expresión) en sus endecasílabos.

El himno del cielo.-

Nucva acumulación de evocaciones, desde sus primeros versos ("Cinintas veces, perdiendo la concicncia/ le que transcurre el tiempo"), y en que son especialmente significativas las siguientes: Bécquer,

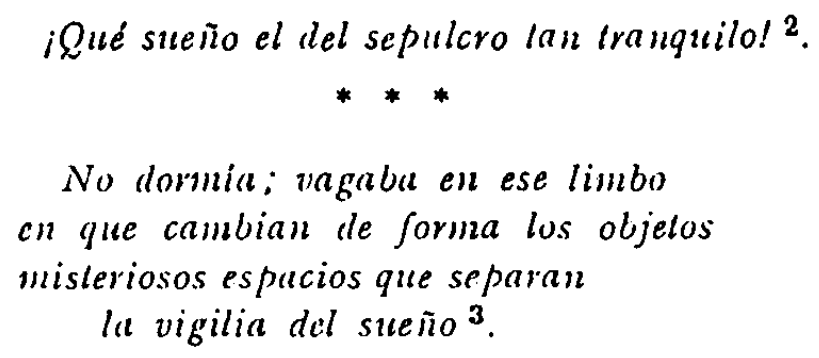

1 \%orriti, Sìn Miartín, Obra citada, p. 274. ("Si al mecer las azules campanillas / de tu balcón...n, dicen los primeros versos de Jécquer en la rima XVI).

$2 \%$ ORRII, SA SAN MAR'Tín, Obra citada, p. 319. No estín muy lejos otros versos del pocta americano: " $X$ en las órbitas negras / sus pupilas fosfóricas chispearon" (Pontifice y rey, Obras, p. 299), y aun aquellos otros: "No, no era un sueño... I riendo ante mis ojos / vi sus pupilas negras..." (No era un sueño, Obras, p. 335).

Solbre los probables origenes en Bécquer de la innagen central: los ojos, las pupilats desisilats..., viase el interesante estudio de J. M.a Dírz TABOADA en La innjer idleal, Madrid, C. S. I. C., 1965, pp. 34-40, en que prueba los antecedentes esproncedianos.

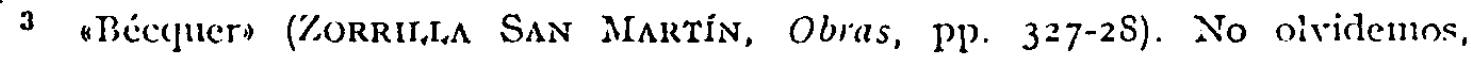
sin embargo, que las palabras de Bécquer fueron "No podia ser», según vemos en el manuscrito autógrafo de El libro de los Gorriones en la Biblioteca Nacional ke Madrid. Claro que \%orrilla San Martin no pudo ver tal autógrafo sino la corrección en el sentido pudo por porla, que Correa y Campillo estamparon ya en la jrimera edición de las Rimas del poeta español. 
y Zorrilla San Martín:

En cl sueño tranquilo de la lierra, deben sonar ast tambien los muertos.

Despuds de ese inlcrvalo, sin caracler de vigilia ni sueño 1.

Sin que ello agote las abundantes reminiscencias becquerianas del poema americano.

Tiss ojos.-

Pequeño poema de ocho versos, los cuatro primeros de los cuales:

Si me asomo a tus ojos brillantes, tall verdes, tan verdes, cu cl campo mina estrella calda misar me parcec

proceden claramente de la rima XIII, cuya última estrofa proporcionó estructura y léxico:

Tu pupila es azul, y si en su fondo como "tu punlo azul de luz radia una idea, me parece en al cielo de la larde

Iuna perdida cslvella!

\section{Buscándola.-}

Estructura sintáctica, anisometría, tema y léxico, colocan este poema junto a la rima XVI de Bécquer, de la que indudablemente procede. Unos cuantos versos de Zorrilla San Martín nos evitarán tener que reproducir la composición entera:

Si en la noche callada, los vumores

su dulce voz remedan...

Si al suspirar aromas el silencio, su aliento a mi alma llega... ${ }^{2}$.

1 En la opinión más generalizada. No falta quien dé por fecha 1857 (Li. ANDERSON IAmERT: Historia de la literatura hispanoamericana, México. l'ondo de Culturá Econónica. Breviarios, 195.1).

2 Aunque incluje poemas que descle is $7 .+$ fue publicanclo en wa listrellan, poriexlico de Montevidio, la ciuclad natal del poeta. 


\title{
La sombra negra.-
}

Una vez más la presencia del sevillano en la siguiente estrofa:

\author{
En vano we revuclvo \\ en mi deshecha cama por no verla... \\ Clavada en la pared, siempie me hallo \\ solo con ella.
}

en que es patente el recuerdo de las rimas XIV y XLIII; de ambas, en cuanto a la obsesión nocturna alucinante, y en especial de la segunda, en cuanto a los mismos sintagmas expresivos:

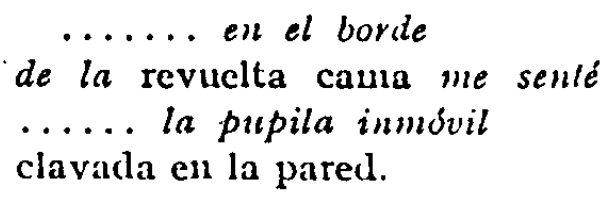

Yo lo sabré.-

lia alabanza de unas pupilas verdes, que se comparan al mar y a las hierbas del prado... nos hace pensar en la rima XII de Bécquer ("Porque son, niña, tus ojos verdes como el mar..."), a que también se acerca en otras leves concomitancias.

\section{El poema de las hojas.-}

Iin sus partes tercera y cuarta: El bosque y Las hojas, respectivamente, se aprecia el recuerdo de las rimas IX y X de Bécquer, de las que ya hemos señalado repetidamente el impacto que en el poeta americano causaron. Il juego amoroso de luz y hojas, troncos y ramas, el beso del amanecer en el bosque..., es tema (y léxico y construcciones a veces) que coincide y coinciden con las rimas antedichas del romántico español.

\section{Las Megras silnelas.-}

Una cle las rimas que mayor impresión debieron de causar a Zorrilla San Martín es la XIV, cuyos versos

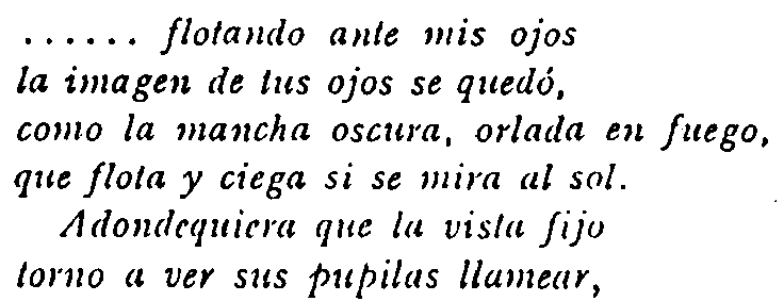


vuelven a estar presentes en este poenla, una vez más:

... el punto negro de conlornos igneos, que al ver el sol en nuestros ojos queda".

'’erminemos recordaudo, como colofón de esta primera parte, (1ue Zorrilla de San Martín, que uunca encubrió su admiración por Bécquer, le dedicó en este mismo libro un hermoso poema en que no le fue difícil (¿cómo, tras lo que llevamos dicho) acercarse al estilo becqueriano, para concluir de su ilusión, por «apasionados imposibles», el "iNo pudo ser!» en que el sevillano se había anticipado, reflexiva y tristemente, en su bellísima rima XII ${ }^{2}$.

\section{La leyenda palria}

De este pocma heroico, largo de $4 \mathrm{r} 3$ versos, se lia dicho que fue escrito en cuatro o cinco noches de febril inspiración, y 110 son su tema y motivos los más a propósito para que el futimo romántico español aparezca como modelo; el ser una "oda de corte heroicon, "epinicio triunfal y lección histórica a la vez», como señalan Díez Echarri y Roca Irrauquesa en obra anteriormente citada, lo acercan más a nuestros poemas vibrantes del 2 de mayo ${ }^{3}$ que al poema de ensueño y dolor callado del sevillano. 'Tal vez por eso no haya sido visto el contacto que, pese a ello, existe entre los dos poemas románticos, en cuanto Zorrilla San Martín se toma un breve descanso, en su ardoroso y patriótico canto, para atender al paisaje y la naturaleza de un amanecer, ell la parte tercera del poema. Como veremos a continuación, ese canto III es una

2 Li. Diez Echarki y J. M. RoCa l'Ranquiss, Historia de la literatura espanola e hispanoamericana, Madrid. Agnilar, 1960, p. 993. Pero peusemos que la primera edición de la obra de Béequer es de 1871 .

2 Aumque terminada en 1886 y retocada posteriormente liasta la edición definitiva de 1923. Parece ser que desile 1879 u 80 estaba ya trabajando en ella.

3 lin ese terreno seria mis fácil scĩalar concomitancias. Véanse, como ejenplo al azar, aquellos versos finales:

\footnotetext{
$Y$ siempre piensa en que tu heroico suelo no mide "n palmo que valor no emane: Pisas tumbas de héroes...
}

muy probablemente no del todo ajenos a la famosa décima del conocido poema de Beruardo López. 
total reminiscencia becqueriana, que ora aquí, ora allá, puede espigarse en tono, innágenes y léxico a lo largo de las Rimas.

Comencemos por presentar, como núcleo del canto de Zorrilla San Martín, el nacer de la aurora:

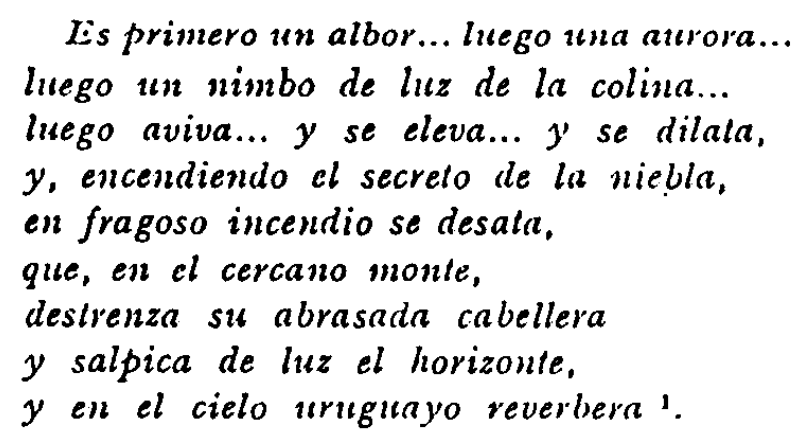

Compárese con la primera estrofa de la rima LXII de Bécquer:

Primero es un albor trémulo $y^{\prime}$ vago
rayo de inquieta luz que corta al mar;
luego chispea y crece y' se dilala
en ardicnle explosión de claridad ${ }^{2}$.

Según puede verse, la fuente es inmediata, y lo es tanto en los versos citados, que el poeta uruguayo debió de escribir dicho fragmento teniendo a la vista los versos de Bécquer.

A idéntico comienzo ("Primero es un albor" / "lis primero un albor») sigue en anbos un segundo verso de valor equivalente ("rayo de inquicta luz» / "luego un nimbo de luz») que no podía ser idéntico en su totalidad por imperativos geográficos: Bécquer, que describe la Aurora, lo hace en su paisaje clásico, tópico ya, junto al mar, nacimiento absoluto del día ("rayo de inquieta luz que corta el mar»). Zorrilla San Martín que describe una aurora, "en el cielo uruguayo", tierra adentro, ha de sustituir el mar por la montaña ("luego un nimbo de luz de la colina").

A continuación un tercer verso definitivo en nuestra comparacion (aluego chispea y crece, y se dilatan//(luego aviva... y se cleva... y se dilata»). Zorrilla adopta idéntica estructura ternaria, idéntico valor semántico en cada uno de los tres términos enfrentados uno a uno, e identidad formal incluso en el "luego...", "se dilata», $y$ la polisindeton "y... y... y".

1 JUAN ZORRILIA Dr: SAN MAR'Tín, Tabaré (Novela ell verso) y La leyenda pultia. Prólogo de Vicentrs Clavei, Barcelona, Tercera edición, Cervantes, 1927. 1). 271.

2 Gus'ravo Anotipo Bríceuir, Obras Completas, Madrid. Aguilar, I961, p.479. 
La equivalencia queda reforzada por la igualdad absoluta que en el "se dilata" hallamos precisamente en el axis rítmico.

Al cuarto verso de Béçuer ("en ardiente explosión de claridad》), corresponden dos en el poeta uruguayo ("y, encendiendo el secreto (le la nicblia, / en fragoso incendio se desatiu), acaso porque en un momento de rima consonante, necesitaba un "desata" junto al anterior "dilata", y separar cufúnicamente dos palabras demasiado cercanas: "encendiendon e (incendion.

Iin cualquier caso, los términos que están ahora en correspondencia entre ambos poetas son, claro está: "ardiente explosion" frente a "fragoso incendio", y acaso "claridad" con "encendiendo", en correlación de dos conceptos lumínicos y uno de violencia e intensidad, en cada escritor.

Pero $n 0$ son ésas las únicas resonancias becquerianas del fragmento, auncue si las mas patentes. Cuando al comenzar el mismo canto III nos dice Zorrilla San Martín que

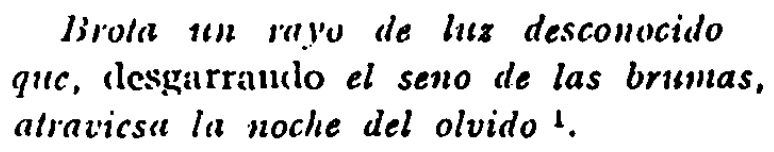

el recuerdo de aquel

valle de etcrnas nieves $y$ de elernas melancólicas brumas

donde habile el olvido'.

de la rima IxVI de Bécquer, wos parece evidente, sobre todo reforzado por aquellos versos finales de la rima LXXI del mismo poeta sevillano:

Entró la nochc, y' del olvido en brazos... ${ }^{3}$.

Y sigue el canto III y el asomar clel alba en Zorrilla San Martín:

Despierlan los barqueros... ya es la hora:

$\because$ al chocar de los remos sobje el rio,

"lzan la bariorola de la aurora

de ritmo audaz y cadencioso brio,

ila eterna barcurola redentoral".

\footnotetext{
1 Obra cilada, p. 271.

2 Gustavo Adoltro Bíceulir, Obra cilada, p. $4^{80}$.

3 Gustavo Adolfo Búclquer, Obja cilada, p. 484 .

- Zokriti.a S.AN MIAktín, Obra y página citada.
} 
P'ues bien, ya dentro del evidente clima becqueriano en que se desenvuelve esta parte de La lcycnda patria, no está lejos una rima, la LXXII, cuyas tres primeras estrofas encierran un léxico no demasiado alcjalo del que vamos examinando, pero cuya cuarta estrofa:

$$
\begin{aligned}
& \text { Ast los barqueros pasaban cantando } \\
& \text { la eternit canción. } \\
& \text { y al golpe de remo sallaba la espima } \\
& \text { y herlala el sol } \text {. }
\end{aligned}
$$

de barqueros que cantan la eterna canción ("eterna barcarola») al golpe de remo ("el chocar de los remos"), al pasar, rompe un tanto bruscamente la secuencia total del poema en uno y otro escritor, no debe ser ajena a la inspiración de Zorrilla San Martín.

'Ianto más cuanto que otros versos del mismo fragmento:

Cacn de los sances las dormidas arpas por impalpable mano arrebaladas ${ }^{2}$.

nos recuerdan esa rima VII de Bécquer, tan cara al uruguayo, como tendremos ocasión de comprobar más tarde, mientras otros aún:

al beso de la luz se alza la guerra, $y$ brotan de la ticrra palpitantes recuerdos a raudales en luminosa ebullición sonora, los átomos alados nadan en luz en torno de la aurora $y$ despiertan los cantos olvidados ${ }^{3}$.

se encuentran totalmente sumergidos en la atmósfera y el léxico del poeta sevillano, sobre todo de sus rimas primeras:

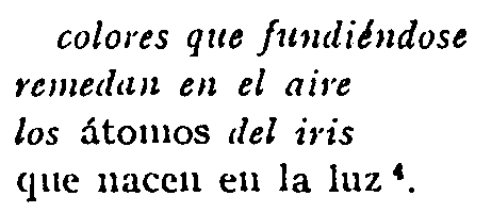

Mientras las ondas de la luz al beso palpiten encendidas: mientras el sol las desgarrarlas nubes

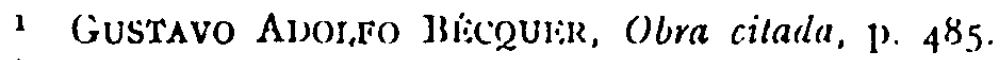

2 \%окRHi,a SAN Mak'tin, Obra y paigina citada.

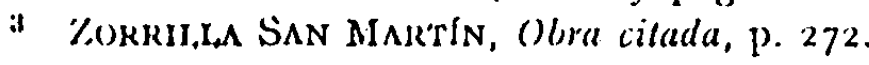

- Gustavo adotio Biccuuir, Obra cilada, p. 4fi (Rima III). 
de fuego y oro vista;

mientras el aire en su regazo lleve

perfumes $y$ armonias '.

y am de las rimas $I X$ y X:

Los invisibles itomos del aire en derredor palpitan $y$ se inflaman; el cielo se deshace en rayos de oro; la tierra se estremece alborozala.

Oigo flotando en olas de armonia rumar de besos...........2.

cuyo léxico (véase el subrayado, que es nuestro) nos exime de una mayor insistencia respecto a las relaciones indudables que hemos ido concretando entre este canto III del poema de Zorrilla San Martín La lcjenda patria y las Rimas de Gustavo Adolfo Bécyuer.

Aquí ya han sido muchos los críticos que repetidamente han scñalado, como al principio indicábamos, las relaciones entre los dus poetas románticos, o, por mejor decir, cuánto debe Zorrilla de San Martín al sevillano. "Bécquer fue el que le enseñó a impostar la voz. Bécquer 110 fue una fuente accidental, sino un espiritu afín que le mostró el camino del estilo. A la nórdica vaguedad de Bécquer debió su ruta. Avanzó por clonde Bécquer ya había avanzado: la alusión a estados de ánimo fluctuantes entre la realidad y el sueño; la sospecha de un misterio que al mismo tiempo nos envuelve y está dentro de nosotros... De Bécquer tomó junto con su delicadeza, la simplicidad del verso» ${ }^{3}$.

l'ues bien, vamos a señalar concretamente, en el poema uruguayo, esas influencias becquerianas, puntualizando los momentos en que son más evidentes, dado que fundamentalmente se ha advertido el aire de misterio, el tono de voz, el espiritu afín que los hermana, la semejanza del verso... en líneas generales y a grandes trazos y visión conjunta.

1 (justavo Adolfo Bícquer, Obra cilada, p. 443 (Rima IV).

2 (iustavo Anotfo Bíceutik, Obra cilada, p. 449 (Rima X). La aurora del amor, el alba de Cupido, pudiera apostillarse esta rima becqueriana.

3 Dice Andinson Imbers de \%orrilla San Martin, relacionando Tabaré con el porata sevillano (Historia de la literaliua hispanoamericana, México. londo de cu!tura cconúmica, 1954. pp. 194-95). 
Iil poema Tabarć está dividido en tres libros, precedidos de una Introducción también en verso, y cada uno de aquéllos consta, a su vez, de 2,6 y 6 cantos respectivamente, dejando aparte ya los fragmentos en que cada uno de estos últimos está subdividido. Aś, pues, una Introducción y $\mathrm{I}_{4}$ cantos (en 3 libros) constituyen la obra.

\section{Introducción.-}

Decíamos al comentar La lcycuda patria, que la rima VII de Bécquer era cara al poeta uruguayo, como podriamos comprobar muy pronto. He aquil las primeras resonancias en Tabaré:

I.cvantaré la losa de una tumba;

e intcrnindome en ella, encenderé en el fondo el pensamiento "ue alumbrarii la soledad inmensa.

Dadme la lira, $y$ vamos............

Al clesgrimarse las polenles notas

de sus heridas cllerdas, clespertarin los ecos que han clormido sueño de siglos en la oscura huesa ${ }^{1}$.

Iil poeta americano parte de la imagen de Bécquer, la supone, para, convirtiendo en actividad lo que en ella era reposo y genio dormido, alumbrar el "ángulo oscuro" en que duerme un "sueño de siglos" y ponerle ('ll pie como Cristo a Lázaro desde el fondo de su "oscura huesa". No es necesario insistir en la clara simbología que anuda a la rima de Bécciuer las expresiones de resurrección y losas levantadas del sepulcro. La luz, las notas desgranadas de unas cuerdas heridas de nuevo... El léxico, cn suma, formal o semánticamente, nos dan el punto de arranque de la Int roducción.

Jil scgundo fragmento de ella es una invocación a los poetas, al lector que se sienta tal:

1 \%okkit, IA SAN MLARTí, Obra citada, pp. 17-18. No se nos oculta que becquer uo fue acui (y en otros momentos aducidos) el creador primero de semejante intagen. l'ero el heche de aculit \%orrilla San Martin, como verenos, una y otra ve\%, a imigenes del poeta sevillano, nos obliga a pensar que fue alí de clonde heloic su inspiracion sin necesidad de acudir ocasionalnente a flentes prinigeniiats. 
Vosotros. Los qua amulis los imposibles, los que vivis la vida de la idea;

los que sabeis de ignotas muchedumbres, que los espacios infinitos pueblan... ${ }^{1}$.

y... a Bécruer inspirador, amante del imposible (recordamos la rima XI: (yo soy un sueño, un imposible... / ...jOh ven, ven túln) y de tantas otras cosas que Zorrilla invoca en esos versos:

$$
\begin{aligned}
& \text { yo vivo con la vicla } \\
& \text { sin forma de la idea }{ }^{2} \text {. }
\end{aligned}
$$

Lil tercer y último fragmento de la Introducción es acaso el más plena, intencional y formalmente becqueriano. Comencemos por decir que tiene el mismo papel que al frente del Libro de los gorriones o de las Rimas del sevillano su Introducción sinfónica en prosa. El mismo mundo cático que se rebela desde el fondo oscuro del cerebro buscando una salida a la realidad, y que justifica por sí mismo el poema (o las Kimas) gue amanece:

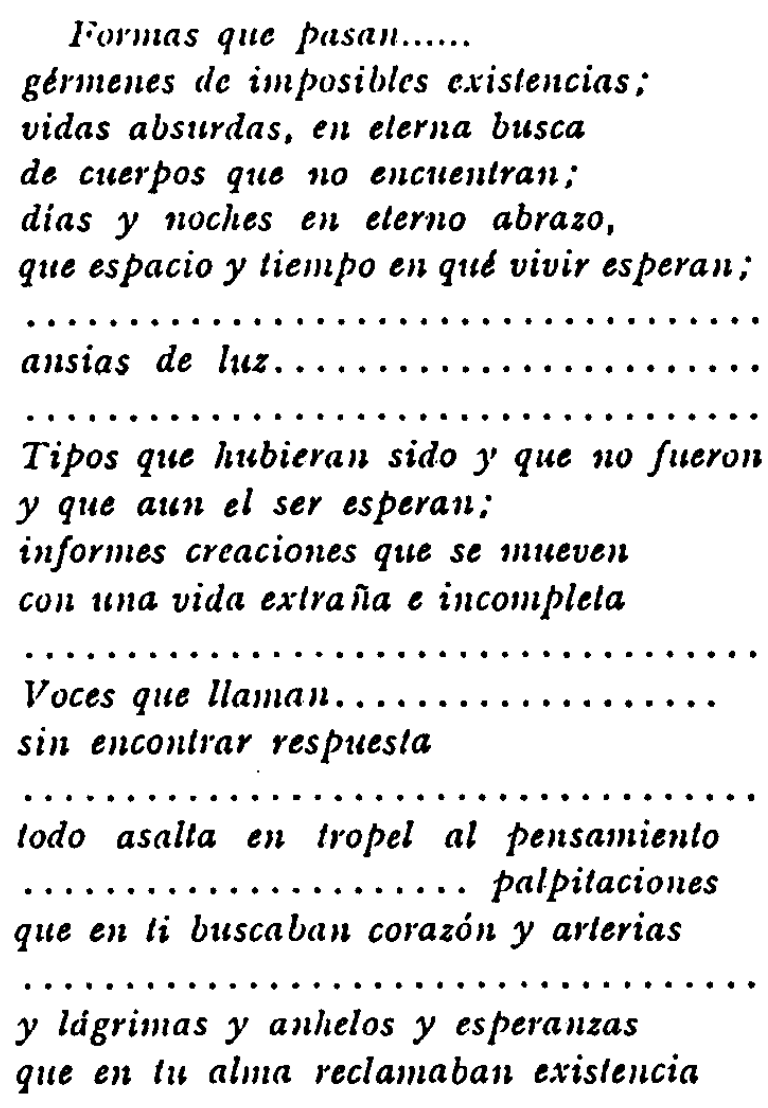

1 Zorrili,a San MLARTí, Obra cilada, p. 18.

2 Rima V. Gustayo Adolio BúceULê, Obra citada, p. 444. 
iAhl no, no pasarás, como la nube (que el agua inmóvil en su faz refleja; como esos sueños de la media noche que en la mañana ya no se recterclan: Yo te ofrezeo, joh ensueño de mis diast la virla de mis cantos, que en la tiema vivircin mis que yo... ¡l'alpita y anda, forma imposible de la estirpe nueslralu'.

La cita es larga... y corta, porque, a decir verdad, el mismo aire y léxico becqueriano de los versos citados, tiene todo este último fragmento, y tanto valor comprobatorio tiene lo desdeñado como lo aqui recogido. No necesita insistencias al ser comparado con la Introducción sinfónica de Bécquer, pero permítansenos dos cortas prucbas de identidad que llegan hasta el léxico: "Conmigo van, destinados a morir conmigo, sin que de ellas quede otro rastro que el que deja un sueño de media

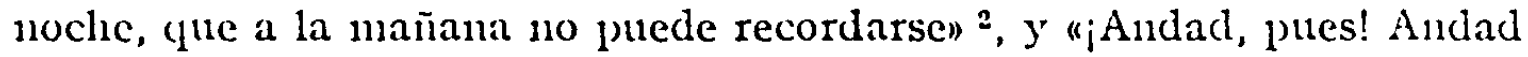
$\mathrm{y}$ vivid con la única vida que puedo darosı) ${ }^{3}$.

lero no se crea, por estas citas y pruebas de las miltiples que podrían darse, de la relación señalada, que sólo con esa Inlroducción becqueriana tiene concomitancias la de Tabaré. La rima III, en sus dos partes dedicadas a describir la inspiración y la razón, respectivamente, informan, a su vez, ell gran manera, ese tercer fragmento de la Introducción de Tabaré, pues que asimismo nos describe Zorrilla San Martín sucesivamente la noche del simbólico sepulcro ("el caos de la mente") y la luz del pensamiento "que en su seno penetra / a hacer inteligible lo coufuson.

Los ecos se suceden ininterrumpidamente tanto en su primera, (Bécquer:

\author{
Colores que fundiéndose \\ remedan en el aire \\ los alomos del iris \\ que nadan en la luz
}

1 \%ORRILIA SAN MARTÍN, Obra citada, pp. $20-25$.

2 Gustavo Adolfo Bécquiz, Obra cilada, p. 45. A su vez, los los versos anteriores proceden, probablemente de aquellos de la rima $\mathrm{AXV}$ del poeta sevillano:

que pasa como la mube

del mar sobre el ancho espejo (Obras, p. 458).

3

Gustavo Adolio IBicluir, Obra cilada, p. 46. 
cadencias que no tienen

ui ritmo "i compás'.

y'Zorrilla San Martín:

Colores que se fundeu $y$ repelen en inguielud elerna ansias de luz, primeras vibraciones que no hallan ritwo...... ${ }^{2}$ )

como en la segunda parte. Bécquer:

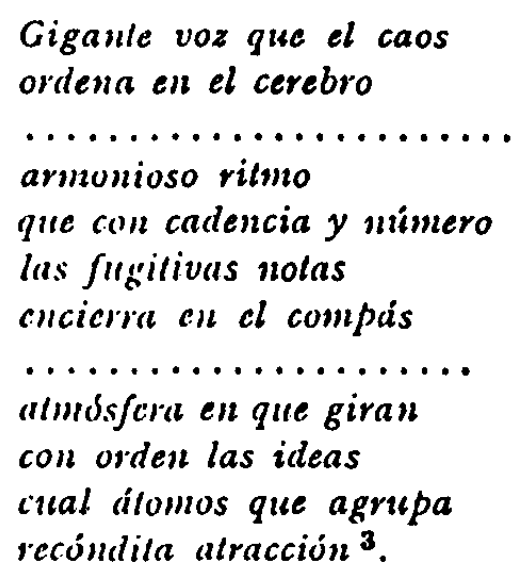

y Zorrilla San Martín:
El caos de la mente que pujante
la inspiración ordena
....................
Todo asalla en tropel al pensamiento
que en sil seno penelra
....................
a consagrar del ritmo y del sonido
la dulce unión eterna
....................
alli cunjo en mi mente, obedeciendo
a "lna alracción secreta... 4 .

I en el mismo fragmento, como en amasijo informe de influjos que se arremolinan en ese caos que uno y otro poeta describen, otros motivos

1 Lustavo Adolfo Bíceuier, Obra citada, p. 448.

2 7.ORRIILA SAN MLARTIN, ObIa cilada, p. 21.

3 Gustaro ADUifo Bieceuis, Obra cilada, p. 442.

- Tukni,l,a SAN Martí, Obra cilada, pp. 20-23. 
y rimas becquerianas se reflejan distintamente $y$ con fuertes reminiscencias $\mathbf{1}$.

Véanse, como ejemplos más característicos, aquellos versos de la misma Introducción de Taburé:

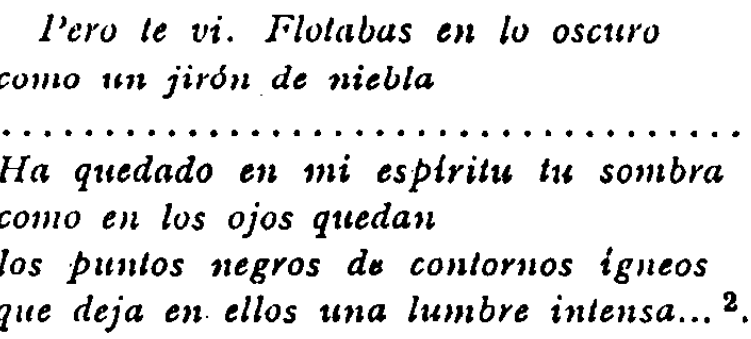

que indudablemente proceden de la rima XIV de Bécquer:

Te vi un punto, y flolando ante mis ojos la imagen de tus ojos se quedto, como la mancha oscura, orlada en fuego, que flutu y ciega si se mira el sol ${ }^{3}$.

\section{Canto primero.-}

Decíamos anteriormente que, cuando en un poema heroico, patriótico, como La leyenda patria, aparece Bécquer, ha de hacerlo en los momentos de paz, en que el paisaje se incorpora serena e intinamente al sentir del poeta uruguayo. Algo semejante ocurre con Tabaré, si bien los resquicios para infiltrarse son aquí mucho más amplios y numerosos.

En lo mucho narrativo que el poema contiene, corto papel puede desempeñar el lírico puro que el sevillano es; pero, cuando Zorrilla se siente invadido por la música del paisaje y los anhelos misteriosos del

1 De la rima I, por ejemplo, en aquel anhelo de crear un "himno gigante y extrañon, cn "palabras que fuesen a un tiempo/suspiros y risas, colores y notas. ("Lineas, colores, notas de un acorde / disperso...", en Zorrilla San Martín).

2 ZORRII, IA SAN Martín, Obra citada, p. 24. Aún puede observarse mayor cercania en una primera redacción, del poema Las negras siluelas, que forma parte del libro Notas de un himno (J. Z. DE SAN MIARTín, Obras Completas, Montevidco, Imprenta Nacional Colorada, 1930. T. I, p. 319):

$$
\begin{gathered}
\text { O el punto negro de contornos igneos } \\
\text { que al ver el sol en muestros ojos queda. }
\end{gathered}
$$

3 Gustavo Adolio Bi:cQuin, Obra cilada, p. 453. 
alma sencilla de Tabaré (elemento no menos frecuente que el narrativo en la obra), Bécquer suele reaparecer como un eco siempre presente.

Así, en el primer fragmento del canto primero, égloga en apacible naturaleza virgen en que

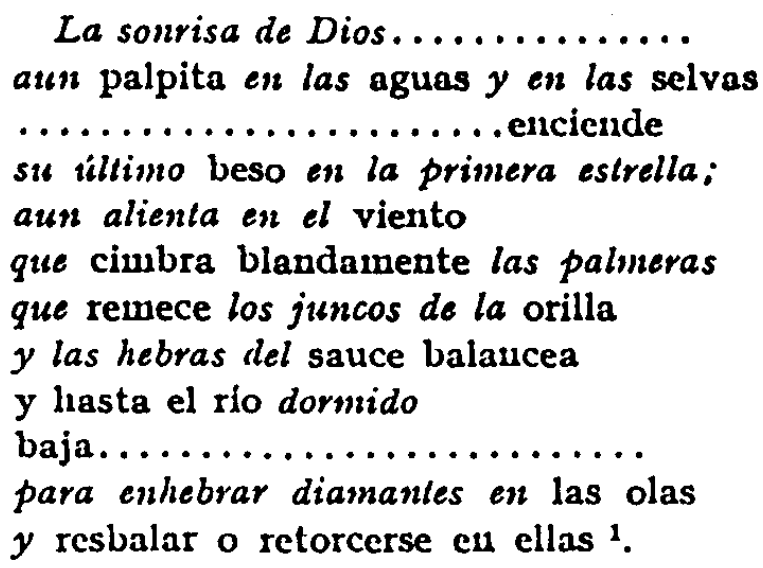

I as scmejanzas y aun identidades (semánticas, pero también léxicas con excesiva frecuencia para ser casuales) con las rimas IX y $\mathrm{X}$ de Bécquer son muy grandes cuando éste nos describe asimismo la armonía de naturaleza inclinada al amor que integra la creación. Son las rimas que una comienzan: "Besa el aura que ginc blandamente" (rima IX) y "L,os invisibles átomos del aire" (rima $\mathrm{X}$ ). El subrayado nuestro quiere llamar la atención hacia términos de ambas que, por demasiado conocidas, no incluimos. Compararemos únicamente el fin del fragmento con el final de la rima IX de Bécquer:

$Y$ hasta el sauce, inclinándose a su peso el río que lo besa, vuclve un beso ${ }^{2}$.

como colofón de este primer sondeo a unas indudables y continuas relaciones.

Canto segundo.-

Pero el eco de la rima $\mathrm{X}$ se percibe más claramente en el fragmento quinto de este canto segundo, en que Zorrilla San Martín nos describe el sencillo bautismo de Tabaré por su madre, y la expectación casi so-

1 Tokrilia San Martín, Obta cilada, pp. 27-28.

2 Gustavo dDolfo Búceulir, Obra citada, p. 449. 
brenatural con que la naturaleza virgen y el misterio asisten a aquel acto que no por su elementalidad pierde en su valor sublime:

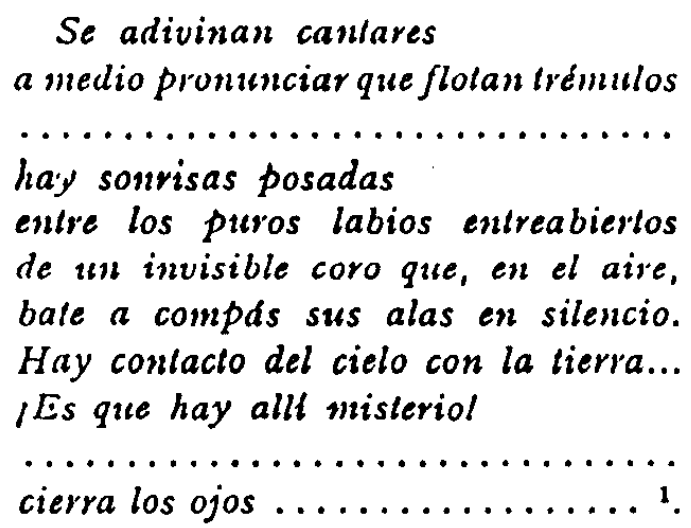

Aquí, si bien no puede descartarse el recuerdo evangélico, en el bautismo de Cristo en el Jordán, el lenguaje, la expresión, tiene en la rima $\mathrm{X}$ de Bécquer su modelo ${ }^{2}$.

Ya no aseguraríamos 10 mismo, pese a las apariencias, en el canto a su hijo 'labaré, que la madre moribunda entona para conciliar su sueño. Iil ritornello "duerme" de aquel poema, igualmente repetido en la rima XXVII de Bécquer, y algunas otras coincidencias léxicas o expresivas (sol, azull, sonrisa, boca...) no nos parecen suficientes en la misma medida, en tema de tan necesarias concomitancias en cualquier autor.

Libro segundo: canto primeru.-

Antes de entrar en la descripción narrativa, Zorrilla San Martín se pregunta por el misterio de la belleza, la poesía y el universo, en un primer fragmento de gran valor, cuya cuarta estrofa dice así:

1 ZORRII,I,A SAN MARTí, Obra cilada, pp. 44-45.

- Recuérdese y compárese con Bécquer:

Los invisibles atomos del aire
en derredor palpitan y se inflaman:
el cielo se deshace en rayos de oro:
la tierra se estremece alborotada.
Oigo flotando en olas de armonia
rumor de besos y batir de alas:
mis parpados se cierran... iqué sucede?
¿dime?... iSilencio!... ilis el amor quc pasa!




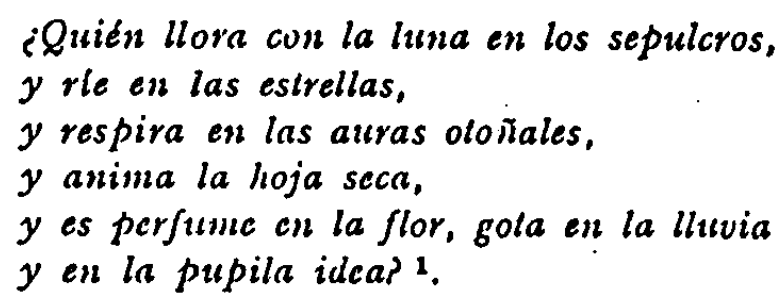

Iis fragmento en que no creemos equivocamos al sorprender la pregunta a una respuesta que Bécquer da en su rima V:

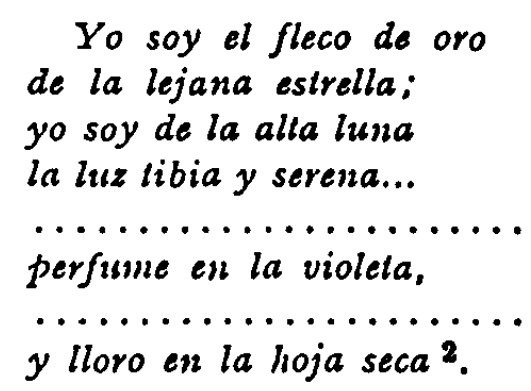

I,a similitud léxica, reforzada sobre todo por la construcción sintíctica nada frechente ("¿quién es perfume en la flor? // yo soy perfume ch la violetan) y sin cunbargo idéntica, se hace mayor al repetirse aquí la expresión: "L Los que vivis la vida de la idea", cuyo origen ya indicamos nos parecía encontrar en la primera estrofa precisamente de esa rima. V:

yo vivo con la vida

sin forma de la idea.

Canto tircero.-

Un recuerdo de esa misma rima $V$ ( $y$ aun, a veces, de la $X V$ ) se observa en el fragmento cuarto del canto tercero, en que vuelve a la estructura anteriormente señalada:

Que gimes en el viento, que nadas en la licz, que ries en la risa de las aguas del Igmazii ${ }^{3}$.

1 ZORRILIA SAN MLARTín, Obja cilada, p. 54.

3 Gustavo Adolfo Bécquier, Obra citada, pp. 444-47.

3 Zorrinla SAN MARTín, Obra citada, p. 94. Respecto a la rima XV, ell el fragmento a que nos referianos, recuérdese:

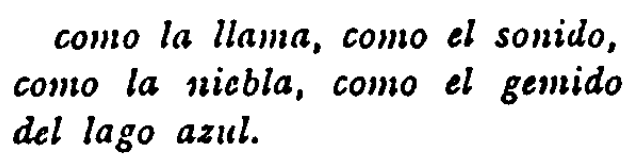

en que hasta el eco fonético (‘del lago azul / del Iguazún), acompaña a la medida. (BícQUER, Obras, p. 454). 
Y no dejemos de consignar, antes de pasar a otro fragmento de Taburé, que en las palabras de éste a la joven Blanca:

iDile al charria que esos ojos tuyos no son los que en sus siceños ve flolar!'.

renace de nuevo el recuerdo de la rima XIV de Bécquer, que ya antes señalábamos.

\section{Libro segundlo: canto quinto.-}

Una vez más, al comenzar un canto, dedica Zorrilla sus primeros versos a una naturaleza cuya belleza le subyuga, y, al identificarse y sentir con ella, los ecos becquerianos reaparecen. In este caso un nuevo amanecer mezcla inágenes anteriormente utilizadas, para crear nuevas formas de belleza:

\footnotetext{
Deslelda en las lintas de la atrora la luz se disolvio de las estrellas;

la risa de los cielos la despertado el himno de la tierra.

No sera necesaria demasiada puntualización para ver aquí de nuevo reflejadas primeramente las rimas IX y $X$ de Bécquer, tantas veces citadas, cn similitud de objetivo (el amanecer, en armonía cósmica) y léxico; en segundo lugar, y ahora en oportunidad semejante a la que ya utilizara en La leyenda patria y hemos señalado, en efecto, en aquel momento: la rima VII ${ }^{3}$. En este último caso, la relación léxica se ex-

1 ZoRrit, SAN MARTín, Obra cilada, p. 97.

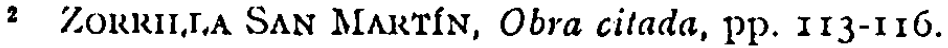

3 Si ahora son arpas que la aurora descuelga de las ramas, entonces cran arpas que de los sauces arrebataba impalpable mano. 
tiende a los versos siguientes de Zorrilla San Martín, en compleja imagen totalmente existente ya en la bellísima rima becqueriana. Digamos, sin embargo, que la descripción del amanecer de este fragmento de Tabarć constituye uno de los momentos más logrados del poema.

\title{
Libro tercero; canto tercero.-
}

Ha cambiado la decoración; el poblado cristiano ha sido atacado en la noche por los indios, y Zorrilla San Martín nos muestra el despertar horrorizado de Blanca entre el griterío:

\author{
¿Duerme? \&O en el vahido indescriptible \\ intermedio entre el sueño y la vigilia \\ la realidad y la ilusion se estrechan \\ $y$ en su espiritu flotan confundidas? \\ Acaso $n o$ dormia. So incorpora: \\ cu el espacio la mirada fija; \\ separa los cabcllos de su frente, \\ $y$ escucha inmóvil, temblorosa, livida. \\ Vedla en el borde del revuelto lecho \\ ¿que ve? ¿Suena? ¿Deliva? \\ ¿Quien derrama en el alma de la virgen \\ ese terror que asoma a sits pupilas? 1.
}

Pues bien, también aquí ha sabido el poeta uruguayo encontrar su inspiración en la obra becqueriana, confundidas las inágenes y expresiones de dos de sus más características rimas, la XLIII y la LXXI:

Deje la licz a un lado, $y$ en el borde

de la revuelta cama me sente. mudo, sombrio, la pupila inmóvil clavada en la pared.

¿Que tiempo estuve asi? No sc: al dejarme

la embriaguez horrible del dolor... 2 .

No donnia; vagaba en ese limbo en que cambian de forma los objetos, misteriosos espacios que separau la vigilia del sueño ${ }^{3}$.

1 ZoRrulia San MLartín, Obra citada, pp. 185-186.

2 Rima ILIII. Gustalo Avor,ro BlícQulir, Obra cilada, p. 469.

3 Rima LAXI. Gusiavo Avorjo BúçQUer, Obra cilada, p. $4^{83}$. 
$\mathrm{Y}$ están suficientemente cerca ambos poetas, como para que el simple subrayado, como siempre nuestro, nos exima de un comentario que surge espontáneamente de la sencilla comparación entre los fragmentos citados.

$Y$.cuando, en los últimos fragmentos del mismo canto, nos presenta el poeta americano la reacción del capitán español al conocer el rapto de que, durante la lucha, ha sido objeto su hermana Blanca por parte de los indios, nuevamente Bécquer está en el fondo ( $y$ aún en la forma) de los versos de Tabaré:

Cuando se lo dijeron

Ia planta vaciló de don Gonzalo:

perdio el mundo las formas a sius ojos

y, para no caer, se asió de un árbol

y ese llanto sin ldgrimas que riega

la raiz del dolor, seco sus parpados

Duros sollo un instante

del abatido joven el lelargo:

un instante mortal en que perdiera

la conciencia del tiempo y del espacio '.

Compárense estas palabras con las que forman la primera estrofa de la rima XLII de Bécquer:

Cuando me lo contaron senti el frio

de una hoja de acero en las entrañas:

me apoyé contra el muro, y un instaute

la conciencia perdi de donde estaba ${ }^{2}$.

A lo que es evidente por la simple lectura (adviértase incluso la identidad de ritmo a veces absoluto, como en el último verso de uno y otro poeta), sólo añadiremos que, en versos siguientes a los que hemos citado, aun hay coincidencias léxicas entre ambos escritores (alma, dolor, mubes, noche...) que corroboran, si faita hiciera, que de nuevo Bécquer ha estado presente en la obra de Zorrilla San Martín, muy intensamente.

\section{Canto cuarto.-}

Scñalemos únicamente, en este recorriclo que en Tabaré realizamos espigando las huellas más destacadas de Bécquer, que los últimos versos del canto cuarto del tercer libro:

1 ZORRII, S SAN MLAR'tin, Obra cilada, pp. 193-195.

2 Gustavo Anohio Bíçuir, Obra cilada, p. 468. 
Como se antan dos fuegos en un sepulcro

al confundirse en una sola llana;

como de dos deseos imposibles

se aman las esperanzas... 1.

están lo suficientenente cerca de las de la rima XXIV de Bécquer:

Dos rojas lenguas de fuego

que a un mismo tronco enlazadas

se aproximan, $y$ al besarse

forman una sola llama... ${ }^{2}$.

Canto quinto.-

Llegamos, finalmente, al último punto de nuestro estudio comparativo. Cuando Tabaré vuelve al poblado cristiano con Blanca, a quien lia conscguido rescatar, entre sus brazos, que la conducen dormida y agotada por las ennociones, Zorrilla San Martín nos describe la cmoción del indio al sentirla junto a su pecho:

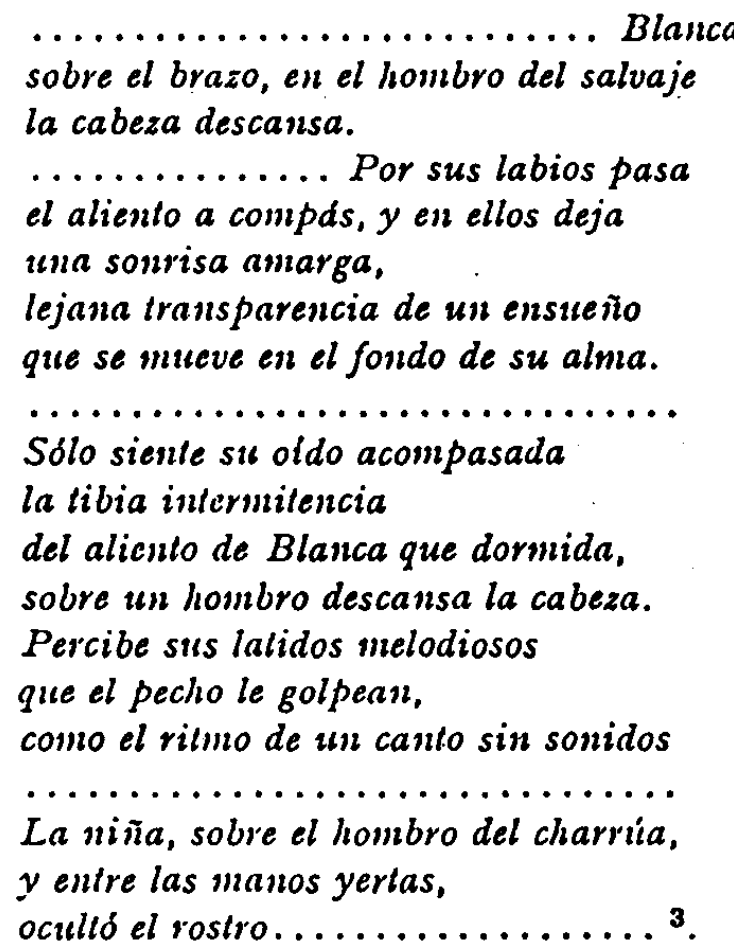

1 ZORRILLA SAN MLARTIN, Obra cilada, p. 220.

2 Gustavo Adorfo BÉcQUier, Obra cilada, p. 457. La semcjanza continúa eu los ejemplos paralelos y siempre de estructura dual de toda la rima del poeta serillano.

3 ZORRII, SA SAN MLARTIN, Obra cilada, pp. 226 a 230. 
Las rimas XXV, XXVII y XL, de Bécquer, en diferentes fragnentos de las mismas, nos of recen momentos semejantes, posibles antecedentes, dentro de la densa red que entre ambos poetas hemos tejido, del buen poeta uruguayo.

Así, véase de la rima XXV:

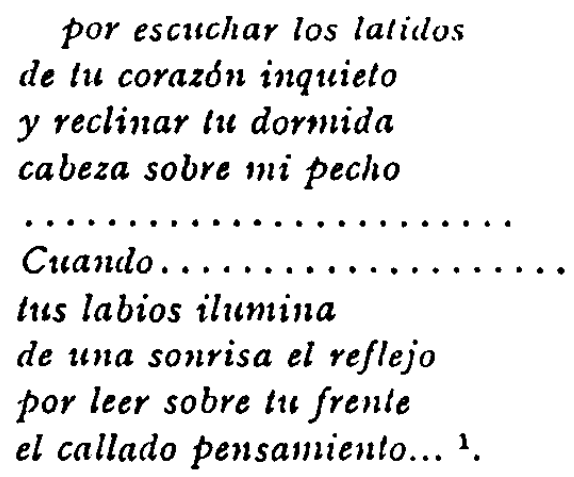

o cu la rima XXVII:

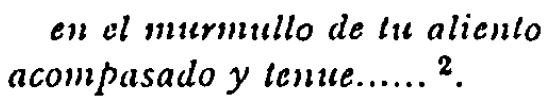

y finalmente en la XL:

Su mano enlre mis manos, sus ojos en mis ojos, la antorosa cabeza apoyada en mi hombro... ${ }^{3}$.

Aunque no sean en esta última ocasión concomitancias tan definitivas cono en otras hemos ido mostrando, sí creemos bastan para demostrar, una vez más, resonancias del poeta sevillano en el uruguayo, terminando con ello este estudio en que nos habíamos propuesto, como indicamos al principio, concretar debidamente esa influencia de Bécquer en Zorrilla San Martín, señalada, sí, repetidamente, pero acaso no debidamente puntualizada.

\section{RAMón Esquer Torres *}

1 Gustravo Adomio Bŕceuin, Obra citada, p. 458.

2 Gustavo Adolfo BícQuir, Obra cilada, p. 460.

3 Gustavo Anor lio BícQuis, Obra citada, p. 460.

(*) Iil autor de este artículo falleció en junio de 1969 , antes de corregir pruebas del mismo. 